CASE REPORT

\title{
INTOXICAÇÃO POR ANTIBIÓTICO IONÓFORO EM RUMINANTES ALIMENTADOS COM VARREDURA DE FÁBRICA DE RAÇÃO - RELATO DE CASO
}

\author{
Anaise Emanuele Resende ${ }^{1}$, Pâmela Aparecida Lima ${ }^{1}$, Mary Suzan Varaschin ${ }^{1}$, Pedro Soares \\ Bezerra Júnior ${ }^{2}$, Angélica Terezinha Barth Wouters ${ }^{1}$, Josilene Nascimento Seixas ${ }^{1 *}$
}

\section{RESUMO}

Antibióticos ionóforos (AI) são fármacos utilizados em animais, principalmente como coccidiostáticos e melhoradores de desempenho. Podem causar intoxicação aguda ou crônica, induzindo lesões musculares esqueléticas e/ou cardíacas. São descritos os aspectos epidemiológicos, clínicos e patológicos de um surto de intoxicação por AI em ovinos e bovinos que receberam sobras provenientes de uma fábrica de ração (popularmente conhecidas como varredura). Quatro horas após o acesso à ração contaminada alguns ovinos foram encontrados mortos e vários outros estavam doentes. Os bovinos manifestaram sinais um dia após ingestão da ração, com morte após 4 a 20 dias. Estes consistiam em inapetência, fraqueza, relutância em movimentar-se, incoordenação, dispneia, decúbito lateral e morte. Morreram 61 ovinos (42,36\% do rebanho) e oito bovinos jovens (24,24\% do lote). Duas ovelhas doentes foram encaminhadas ao Setor de Patologia Veterinária da Universidade Federal de Lavras (SPV/DMV/UFLA). Devido à gravidade do quadro clínico foram submetidas a eutanásia. Na necropsia observaram-se áreas pálidas na musculatura, caracterizadas histologicamente por graus variáveis de necrose e regeneração em músculos esqueléticos e cardíaco. A análise cromatográfica (HPLC) de uma amostra da ração utilizada revelou 97,14 $\mathrm{mg}$ de monensina/kg de ração. O diagnóstico de intoxicação por ionóforos baseou-se nos achados epidemiológicos, clínicos, lesões macro e microscópicas e na análise toxicológica da ração oferecida aos animais. Embora a utilização de "varredura de fábrica de ração" pareça uma opção economicamente interessante aos produtores ela oferece riscos de intoxicação e/ou morte e não é recomendada.

Palavras-chave: Bovinos, miopatia tóxica, monensina, ovinos.

\section{INTRODUÇÃO}

Os antibióticos ionóforos (AI) são utilizados em diversas espécies animais com ação coccidiostática, antimicrobiana, promotora de crescimento e reguladora do $\mathrm{pH}$ ruminal (GONÇALVES et al., 2012). Os principais utilizados são monensina, lasalocida, narasina e salinomicina (BARROS et al., 2007).

O uso inadequado de AI pode causar intoxicação (NOGUEIRA; FRANÇA; PEIXOTO, 2009; RISSI; BARROS, 2010). A evolução do quadro pode ser aguda ou crônica, relacionada a lesões musculares esqueléticas e/ou desenvolvimento de insuficiência cardíaca congestiva. Os sinais clínicos mais relatados são anorexia, diarreia, fraqueza, depressão, incoordenação motora, andar rígido e relutância em movimentar-se, tremores musculares, mioglobinúria, emaciação, dispneia, corrimento nasal, decúbito esternal e morte (SALVADOR et al., 2009).

Este trabalho descreve os aspectos epidemiológicos, clínicos e patológicos de um surto de intoxicação por antibiótico ionóforo em ovinos e bovinos no sul do estado de Minas Gerais.

\footnotetext{
*Artigo recebido em: 26/02/2015

Aceito para publicação em: 27/08/2015

${ }^{1 .}$ Setor de Patologia Veterinária, Departamento de Medicina Veterinária, Universidade Federal de Lavras.

${ }^{1 .}$ Laboratório de Patologia Animal, Faculdade de Medicina Veterinária, Universidade Federal do Pará (UFPA).

*Corresponding author: J.N. Seixas [josiseixas@dmv.ufla.br]. Setor de Patologia Veterinária, Departamento de Medicina Veterinária, Universidade Federal de Lavras (SPV/DMV/UFLA), Campus Universitário, Caixa Postal 3037, CEP 37200-000, Lavras, MG, Brasil. (35) 38295210.
} 


\section{RELATO DO CASO}

Em uma propriedade rural (Itumirim MG) ocorreu um surto de intoxicação com evolução clínica superaguda a crônica após a introdução de ração contaminada por AI na alimentação de ovinos e bovinos. Um lote de 144 ovinos Santa Inês e de corte sem raça definida (SRD) (117 adultos) e outro de 33 bovinos de aptidão leiteira SRD (três vacas e 30 bovinos de 10 a 15 meses) eram criados a pasto e com acesso livre a sal mineral e água; recebiam ração no cocho, especialmente as ovelhas recém-paridas e os bovinos em crescimento e terminação.

O proprietário adquiriu um produto conhecido como "varredura", proveniente da limpeza (sobras) de uma fábrica de ração, que era composto de rações destinadas a diversas espécies animais e que continha monensina. Utilizou-o na alimentação dos animais, apesar de ser indicado pelo fabricante apenas como adubo. Foram fornecidos $10 \mathrm{~kg}$ da ração para os bovinos jovens e, no dia seguinte, oito quilos para todos os ovinos. Quatro horas após os ovinos terem acesso à ração, alguns animais foram encontrados mortos e muitos apresentavam como sinais clínicos principais: inapetência, fraqueza, incoordenação, dispneia, relutância em movimentar, decúbito lateral e gemidos. Até o final do dia morreram 27 ovinos, com evolução clínica entre quatro a 11 horas. Muitos ovinos manifestaram sinais clínicos nos dias subsequentes e três também apresentaram urina marrom-escura. Após 27 dias, $61(42,36 \%)$ de 144 ovinos haviam morrido.

Nos bovinos observou-se apetite diminuído somente no dia seguinte; após dois dias um bezerro estava em decúbito esternal, com tremores, sialorreia e dispneia; ao ser forçado a levantar-se manifestou incoordenação, andar sobre as pinças e aparente fraqueza muscular. O quadro evoluiu para decúbito lateral e morte quatro dias após início das manifestações clínicas. Nos dias subsequentes outros sete tiveram sinais semelhantes, além de focinho seco, diarreia escura, aumento de volume submandibular e dificuldade para beber água. Vinte dias após início dos sinais clínicos o $8^{\circ}$ bovino foi encontrado morto.

Duas ovelhas Santa Inês com idade aproximada de 18 meses foram encaminhadas ao Setor de Patologia Veterinária da Universidade Federal de Lavras (SPV/DMV/UFLA). Iniciaram com sinais clínicos (anorexia, apatia e fraqueza muscular acentuada) no $9^{\circ}$ (Ovino 1 ) e no $15^{\circ}$ dia (Ovino 2) após ingestão da ração. Nos exames bioquímicos séricos, realizados no $10^{\circ}$ (Ovino 1) e no $26^{\circ}$ dia (Ovino 2) foram detectados $\mathrm{CK}$ muscular $(14.496$ e $1.060 \mathrm{U} / \mathrm{L})$ e cardíaca (1.098 e 348 U/L) e AST (36 e 660 U/L) elevados. Devido à gravidade do quadro clínico foram submetidas à eutanásia (realizada conforme Resolução $n^{\circ} 1000$ de 11/05/2012 do Conselho Federal de Medicina Veterinária). Na necropsia foram coletados fragmentos de diversos órgãos e fixados em formol a $10 \%$ tamponado, processados pelo método histológico de rotina e corados por hematoxilina-eosina.

As principais alterações macroscópicas foram áreas ligeiramente pálidas na musculatura dos membros e diafragma, no Ovino 2. No Ovino 1 havia estriações delicadas mais claras no miocárdio, além de edemas cavitários e pulmonar. $\mathrm{Na}$ avaliação histológica havia miopatia e cardiomiopatia polifásicas em ambos os ovinos (Figura 1), no Ovino 1 predominaram necrose hialina e flocular e, no Ovino 2, regeneração dos segmentos musculares necróticos. Também havia congestão em fígado, pulmões e rins no Ovino 1. 


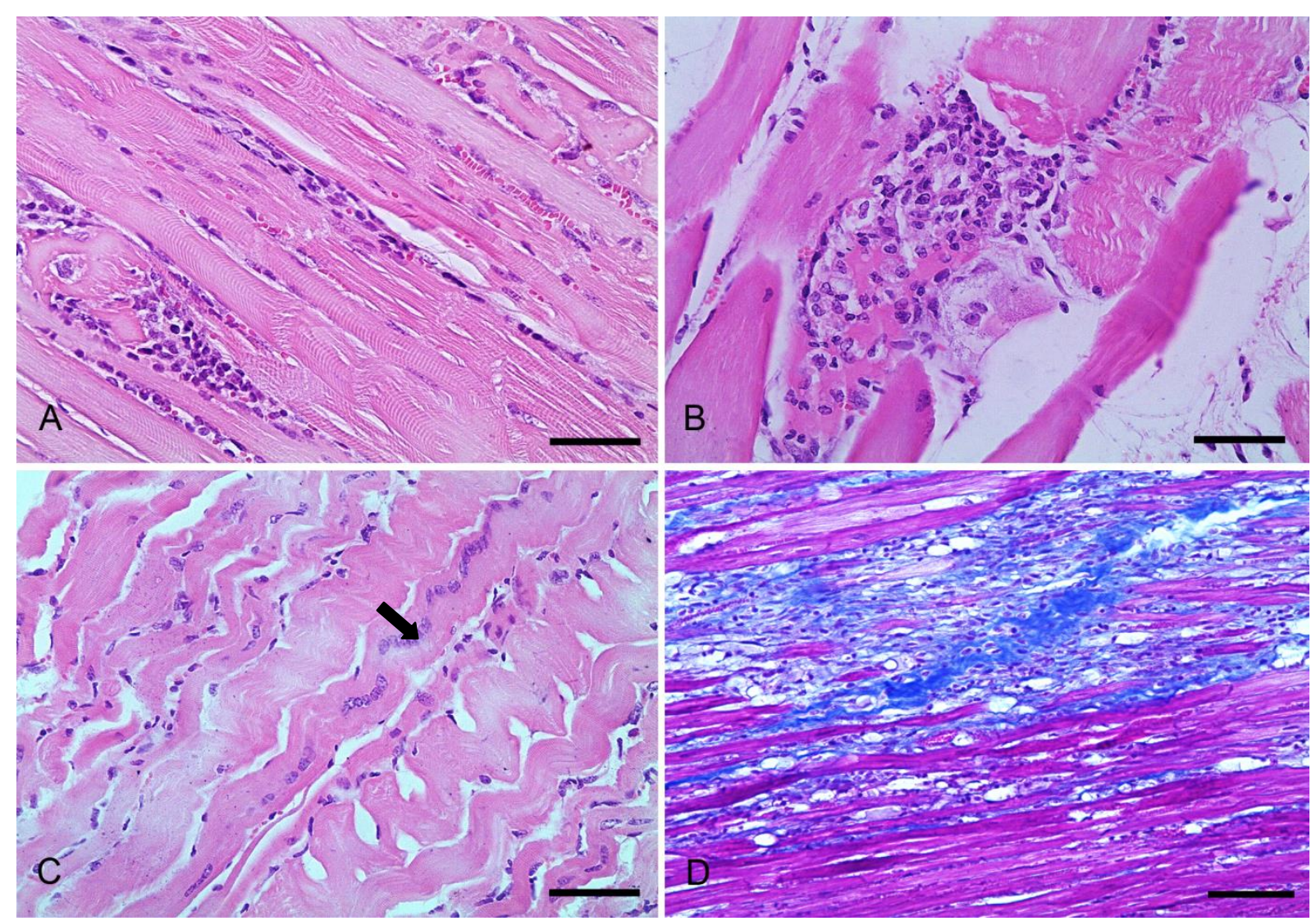

Figura-1. Aspectos histopatológicos de lesões musculares em ovinos intoxicados por antibiótico ionóforo. Necrose flocular associada a infiltrado inflamatório mononuclear em musculatura esquelética (A), Obj. 20x, HE. Notam-se fibras com maior eosinofilia, sem estriações e parcialmente fragmentadas (B), Obj. 40x, HE. Segmentos com núcleos tumefeitos e alinhados centralmente (indicando regeneração) (Seta) (C), Obj. 20x, HE. Cardiomiócitos necróticos entremeados por fibrose e discreto infiltrado inflamatório mononuclear (D), Obj. 10x, Masson.

Amostras dos quatro sacos de ração utilizados foram coletadas, e enviadas a laboratório para dosagem de monensina através da técnica de cromatografia líquida de alta eficiência (HPLC).

\section{DISCUSSÃO}

O diagnóstico de intoxicação por AI baseou-se na epidemiologia, nos achados clínicos e anatomo-histopatológicos e na dosagem de monensina na ração utilizada.

A intoxicação pode decorrer de erro na mistura do fármaco à ração ou no cálculo das dosagens; da utilização em espécies mais suscetíveis; ou uso em associação com fármacos que potencializam os efeitos dos $\mathrm{AI}$ (NOGUEIRA; FRANÇA; PEIXOTO, 2009), no entanto, sua toxicidade está associada principalmente a má homogeneização e falta de adaptação (SALMAN et al., 2006). No presente surto as mortes ocorreram após uso de varredura de uma fábrica de ração, provavelmente sem homogeneização adequada.
A evolução clínica variou entre os animais nesse surto. A dose tóxica de AI é variável entre espécies (BARROS et al., 2007; NOGUEIRA; FRANÇA; PEIXOTO, 2009). Geralmente, altas concentrações causam intoxicação aguda, com início dos sinais em poucas horas (WOUTERS et al., 1997; FRANÇA et al., 2009), entretanto, em concentrações menores a manifestação clínica pode ocorrer em duas semanas ou mais (BARROS, 2007).

A elevação sérica de $\mathrm{CK}$ indica lesão muscular recente, enquanto a elevação de AST demora cerca de 24 horas para ocorrer (BARROS et al., 2007). A diferença marcante entre os níveis destas enzimas demonstra a evolução dos casos relatados; no Ovino 1 , no qual predominaram lesões necróticas, houve maior elevação da $\mathrm{CK}$, enquanto que no Ovino 2, com predomínio de lesões regenerativas, o aumento da atividade sérica da AST foi mais acentuado.

Embora discretas, lesões macro e microscópicas foram visualizadas, o que auxiliou no direcionamento do diagnóstico. 
Porém, em muitos casos as lesões podem passar despercebidas ou mesmo não existirem (WOUTERS et al., 1997; NOGUEIRA; FRANÇA; PEIXOTO, 2009). Nessas situações a confirmação da intoxicação pode ser feita pela análise de amostras do alimento ingerido ou de conteúdo gástrico, sangue, urina, fígado e coração (BAUTISTA et al., 2014). A dose tóxica é de $12 \mathrm{mg}$ de monensina $/ \mathrm{kg}$ de peso vivo para ovinos e de $22 \mathrm{mg} / \mathrm{kg}$ para bovinos (BARROS et al., 2007). A análise cromatográfica (HPLC) de uma amostra da ração utilizada detectou $97,14 \mathrm{mg}$ de monensina/kg de ração, quantidade bem acima da dose recomendada. Assim, considerando o número de animais acometidos, é provável que a dose de monensina existente em um ou mais sacos tenha sido bem superior à detectada. Além da quantidade de AI ingerida, a sensibilidade da espécie foi determinante para o maior número de mortes em ovinos.

Apesar de parecer economicamente interessante, a utilização de "varredura" de ração deve ser abolida dos sistemas de produção animal e os produtores conscientizados sobre os riscos do produto, especialmente devido à composição desconhecida.

\section{IONOPHORE ANTIBIOTICS POISONING OF RUMINANTS AFTER FEEDING WITH SCRAPS FROM A RATION FACTORY - CASE REPORT}

\section{ABSTRACT}

Ionophore antibiotics (IA) are drugs used in animals, particularly as coccidiostats and growth promoters. They can cause acute or chronic poisoning, inducing skeletal and / or heart muscle injuries. This paper describes the epidemiological, clinical and pathological aspects of an IA poisoning outbreak in sheep and cattle fed with leftovers from a animal ration factory. Four hours after the access to the contaminated feed, some sheep were found dead and several others were sick. The cattle manifested clinical signs one day after ingestion of the feed, with death 4 to 20 days after clinical onset. The signs consisted of inappetence, weakness, reluctance to move, incoordination, dyspnea, lateral decubitus and death. Of the sheep herd 61 (42.36\%), and eight young cattle (24.24\% of the lot) died. Two sick sheep were sent to the Veterinary Pathology Sector, Department of Veterinary Medicine of the Federal University of Lavras
(SPV/DMV/UFLA). Due to the severity of the clinical condition, both were euthanized. At necropsy were observed pale areas in the muscles, characterized histologically by varying degrees of necrosis and regeneration in skeletal and cardiac muscles. It was performed a chromatographic analysis (HPLC) of a sample of feed, which showed $97.14 \mathrm{mg}$ monensin $/ \mathrm{kg}$ of feed. The diagnosis was based on epidemiological, clinical, gross and histological findings, and toxicological analysis of the feed used. Although the use of "scan feed mill" seems an economically attractive option for producers it presents risks and is not recommended.

Keywords: Cattle, toxic myopathy, monensin, sheep.

\section{REFERÊNCIAS}

BARROS, C. S. L. Intoxicação por antibióticos ionóforos. In: RIET-CORREA F., SCHILD A. L., LEMOS R. A. A.; BORGES J. R. (Eds). Doenças de Ruminantes e Equíídeos. 2. ed. Campo Grande: Equali, p. 45-49. 2007.

BAUTISTA, A. C.; TAHARA, J.; METE, A.; GASKILL, C. L.; BRYANT, U. K.; PUSCHNER, B. Diagnostic value of tissue monensin concentrations in horses following toxicosis. Journal of Veterinary Diagnostic Investigation, v. 26, n. 3, p. 423-427, 2014. Disponível em: <http://vdi.sagepub.com/content/26/3/423.full. pdf + html >. Acesso em: 24 fev. 2015.

FRANÇA, T. N.; NOGUEIRA, V. A.; YAMASAKI, E. M.; CALDAS, S. A.; TOKARNIA, C. H.; PEIXOTO, P. V. Intoxicação acidental por monensina em ovinos no Estado do Rio de Janeiro. Pesquisa Veterinária Brasileira, Rio de Janeiro, v. 29, n. 3, p. 743-746, 2009. Disponível em: <http://www.scielo.br/pdf/pvb/v29n9/a11v29n 9.pdf>. Acesso em: 24 fev. 2015.

GONÇALVES, M. F.; MARTINS, J. M. S.; OLIVEIRA, M. V.; CARVALHO, C. C. M.; ANTUNES, M. M.; FERREIRA, I. C.; PEREIRA, C. F.; OLIVALVES, L. C. Ionóforos na alimentação de bovinos. Veterinária Notícias, Uberlândia, v. 18, n. 2, p. 131-146, 2012. Disponível em: <http://www.seer.ufu.br/index.php/vetnot/articl e/view/22411/13548>. Acesso em: 24 fev. 2015. 
NOGUEIRA, V. A.; FRANÇA, T. A.; PEIXOTO, P. V. Intoxicação por antibióticos ionóforos em animais. Pesquisa Veterinária Brasileira, Rio de Janeiro, v. 29, n. 3, p. 191197, 2009. Disponível em: <http://www.scielo.br/pdf/pvb/v29n3/01.pdf>. Acesso em: 24 fev. 2015.

RISSI, D. R.; BARROS, C. S. L. Intoxicação espontânea por antibióticos ionóforos em ovinos no Rio Grande do Sul. Pesquisa Veterinária Brasileira, Rio de Janeiro, v. 30, n. 3, p. 219-221, 2010. Disponível em: <http://www.scielo.br/pdf/pvb/v30n3/05.pdf>. Acesso em: 24 fev. 2015.

SALMAN, A. K.; PAZIANI, S. F.; SOARES, J. P. G. Utilização de ionóforos para bovinos de corte. Embrapa Rondônia, 24 p, 2006, (Documento 101). Disponível em: <http://www.infoteca.cnptia.embrapa.br/bitstre am/doc/708265/1/doc101ionoforos.pdf $>$.

Acesso em: 24 fev. 2015.

SALVADOR, I. S.; PESSOA, C. R. M.; SILVA, T. R.; ASSIS, A. C. O.; SANTOS, K. C.; MEDEIROS, J. M. A.; DANTAS, A. F. M. Intoxicação por monensina em ovinos no semiárido paraibano relato de caso. In: VIII Congresso Brasileiro de Buiatria, 2009. Ciência Animal Brasileira, supl. 1, Anais... Disponível em: <http://www.revistas.ufg.br/index.php/vet/artic le/viewArticle/7798/5588>. Acesso em: 24 fev. 2015.

WOUTERS, F.; WOUTERS, A. T. B.; BARROS, C. S. L. 1997. Intoxicação experimental por narasina em ovinos. Pesquisa Veterinária Brasileira, Rio de Janeiro, v. 17, n. 3-4, p. 89-95. Disponível em: $<$ http://www.scielo.br/pdf/pvb/v17n3-

4/0908.pdf>. Acesso em: 24 fev. 2015. 